\title{
KEGIATAN PENGEMBANGAN MOTORIK KASAR
}

\author{
Arnita Fitri' ${ }^{1}$, Syahrul Ismet ${ }^{2}$ \\ Pendidikan Guru Pendidikan Anak Usia Dini Fakultas Ilmu Pendidikan \\ Universitas Negeri Padang \\ Email: arnitafitri2017@gmail.com, syahrul_unp@yahoo.com
}

\begin{abstract}
ABSTRAK
Penelitian ini bertujuan untuk mendeskripsikan tentang kegiatan pengembangan motorik kasar di Taman Kanak-kanak Kartika 1-63 Padang. Penelitian ini menggunakan pendekatan kualitatif dengan metode deskriptif. Informan dari penelitian ini adalah kepala sekolah dan guru, teknik pengumpulan data yang digunakan adalah observasi, wawancara, dan dokumentasi. Teknik analisis data dilakukan dengan teknik triangulasi data. Hasil kegiatan pengembangan motorik kasar di Taman Kanak-kanak Kartika 1-63 Padang telah terlaksana dengan baik. Kegiatan pengembangan motorik kasar dilakukan dengan cara bervariasi agar anak tidak merasa bosan. Setiap kegiatan pengembangan motorik kasar yang dilakukan lebih menekankan latihan perkembangan fisik melalui kegiatan bermain dan olahraga. Guru melakukan kegiatan pengembangan motorik ka sar dengan cara meniru kegiatan militer tetapi di sesuaikan dengan tingkat kesulitan anak. Guru sudah menggunakan metode yang bervariasi dalam kegiatan pengembangan motorik kasar anak yaitu menggunakan metode bernyanyi, metode demonstrasi, metode praktek langsung, dan metode bermain peran.
\end{abstract}

Kata Kunci :Kegiatan Pengembangan Motorik, Motorik Kasar

\begin{abstract}
This study aims to describe the motoric rough development activities in Kartika Kindergarten 1-63 Padang. This study used a qualitative approach with descriptive methods. The informants from this study were headmaster and teacher. The techniques of data collection used were observation, interviews, and documentation. The technique of data analysis was done by using data triangulation techniques. The results of motoric rough development activities in Kartika Kindergarten 1-63 Padang have been well implemented. Motoric rough development activities were carried out in various ways so that children do not feel bored. Every motoric rough development activity carried out emphasizes physical development training through play and sports activities. The teacher conducted motoric rough development activities by imitating military activities but adjusts to the child's difficulty level. The teacher has used a variety of methods in the motoric rough development activities of children, namely using singing methods, demonstration methods, direct practice methods, and role-playing methods.
\end{abstract}

Key words: motoric development activities, motoric rough 


\section{Arnita Fitri ${ }^{1}$, Syahrul Ismet ${ }^{2}$}

\section{Pendahuluan}

Anak usia dini adalah anak yang berumur dari nol sampai delapan tahun yang mana merupakan masa paling indah (golden age). Anak usia dini merupakan individu yang berbeda, mereka memiliki karakteristik, keunikan serta potensi yang berbeda sesuai tingkatan umurnya. Anak usia dini memerlukan wadah untuk bisa mengembangkan segala potensi yang mereka miliki. Anak usia dini juga memerlukan pembinaan dan rangsangan melalui pendidikan. Magdalena (2012:1) pendidikan anak usia dini merupakan lembaga pendidikan formal sebelum jenjang pendidikan selanjutnya. Melalui pendidikan anak dapat belajar sambil bermain, dengan rangsangan pendidikan juga dapat membantu pertumbuhan dan perkembangan anak.

\section{Menurut Wiyani Dalam}

Hasanah (2016:717-718) pertumbuhan dan perkembangan anak pada tahun pertama sangat penting, dan akan menentukan kualitasnya dimasa depan. Aspek perkembangan yang harus dikembangkan kepada anak usia dini adalah nilai agama dan moral, social emosional, bahasa kognitif, seni, dan fisik motorik. Salah satu aspek yang perlu untuk dikembangkan sebagai bekal diri anak adalah motorik kasar.

Motorik kasar adalah gerakan yang menggerakkan otot-otot besar anak, yang menggunakan kekuatan besar bahkan dapat menggerakkan seluruh anggota tubuh. Menurut Iswantiningtyas (2015:249) motorik kasar adalah kemampuan yang membutuhkan sebagian besar kekutan tubuh anak. sejalan dengan Suryana (2016:152) motorik kasar merupakan perkembangan pengendlian gerak tubuh melalui kegiatan yang terkoordinasi antara susunan syaraf, otak, otot dan spinal cord.

Kemampuan motorik kasar adalah kemampuan yang sangat penting bagi kehidupan manusia. Karena melalui motorik kasar manusia dapat bergerak atau menggerakkan seluruh anggota tubuhnya. Kemampuan motorik kasar yang dimiliki anak tidak bisa terjadi begitu saja melainkan melalui tahapan usia, seperti umur lima 
sampai enam tahun anak sudah bisa melompat dengan kedua kaki, sudah bisa bergantung dan berayun, lomba lari, dan balapan sepeda.

Berdasarkan uraian di atas serta observasi awal yang telah dilakukan oleh peneliti di Taman Kank-kanak Kartika 1-63 Padang. Peneliti melihat keunikan dari kegiatan pengembangan motorik kasar yang dilakukan bervariasi setiap harinya untuk menarik minat anak agar tidak bosan dalam melakukan kegiatan motorik kasar setiap harinya. Kegiatan pengembangan motorik kasar di Taman Kank-kanak Kartika 1-63 Padang dilakukan mulai dari anak berbaris di depan kelas melakukan baris-berbaris dan yel-yel seperti militer. Selanjutnya kegiatan pengembangan motorik kasar dilakukan oleh guru bersama anak seperti permainan-permainan yang lebih menekankan latihan perkembangan fisik anak. Maka peneliti tertarik untuk meneliti tentang kegiatan pengembangan motorik kasar di Taman Kanakkanak Kartika 1-63 Padang.

\section{METODE PENELITIAN}

Jenis penelitian

Jenis penelitian ini adalah deskriptif dengan pendekatan kualitatif.

\section{Subjek Penelitian}

Subjek penelitian ini adalah kelas B1 Taman Kanak-Kanak Kartika 1-63 Padang.

\section{Prosedur}

Peneliti Mempersiapkan instrument, instrument tersebut disusun ketika proses pembuatan proposal penelitian, yang berdasarkan kajian teori. Selanjutnya persiapan sebelum melakukan wawancara, wawancara pertama peneliti lakukan untuk mendapatkan informasi awal sebelum peneliti mulai meneliti. Selanjutnya melakukan observasi, peneliti masuk ke dalam kelas untuk mengamati kegiatan yang dilakukan guru, apapun yang peneliti temui pada saat itu peneliti catat pada lembar observasi. setelah melakukan observasi peneliti memasukkan hasil penelitian pada hari tersebut. Selanjutnya melakukan reduksi data, setelah peneliti melakukan observasi, wawancara, dan mengumpulkan foto dan video sebagai bukti dokumentasi 
maka selanjutnya peneliti

mendeskripsikan hasil data yang

telah di dapatkan.

\section{Teknik Pengumpulan Data dan}

\section{Instrumen}

Teknik pengumpulan data pada jenis penelitian deskriptif kualitatif dalah teknik observasi, teknik wawancara, dan teknik dokumentasi. Berikut ini instrument yang peneliti gunakan :

1. Format Observasi

Tabel 1. Contoh Format Observasi PenelitianPengembangan Kegiatan Motorik Kasar di Taman Kanak-kanak Kartika 1-63 Padang.

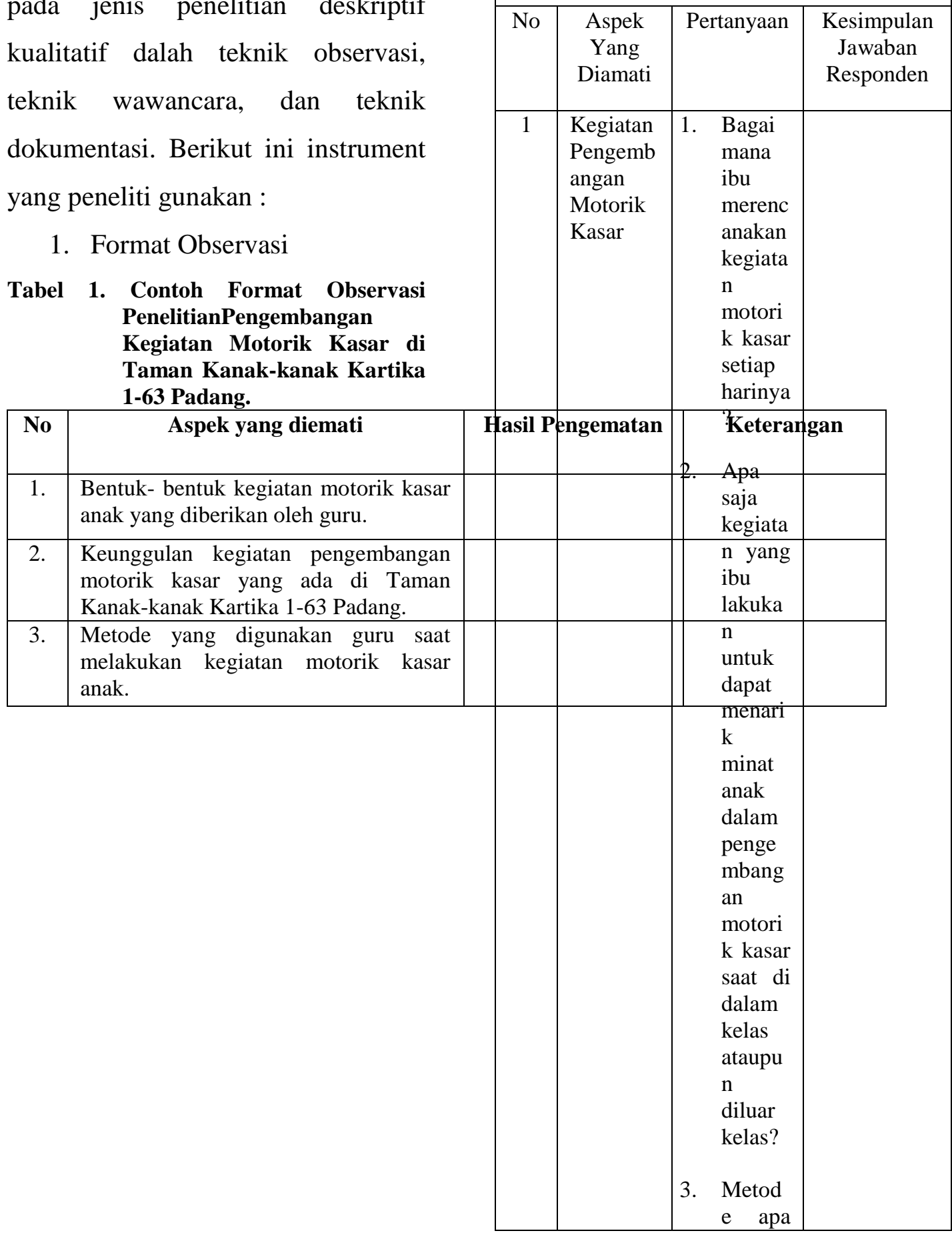

Tabel 2. Contoh Format

WawancaraKegiatan

Pengembangan Motorik Kasar di

Taman Kanak-kanak Kartika 163 Padang

\section{Informan \\ Tanggal :}




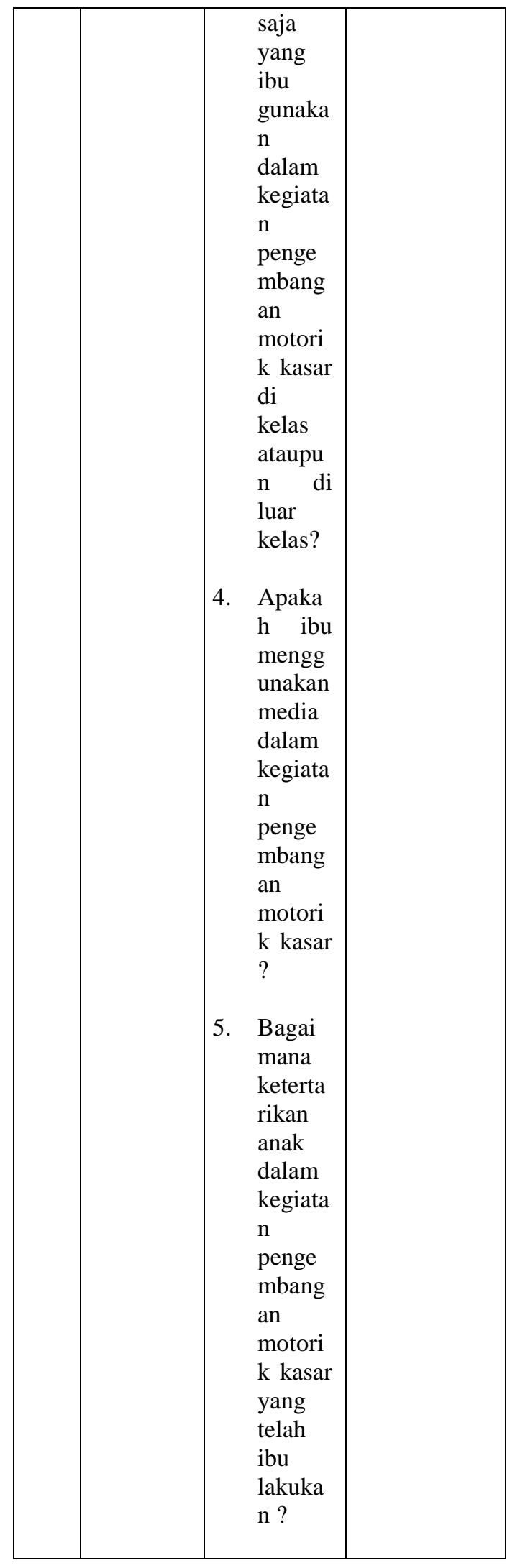

3. Format dokumentasi

Dokumentasi digunakan sebagai bukti bahwa peneliti telah melakukan pengamatan terhadap satu hal yang di teliti.

\section{Teknik Analisis Data}

Data ini peneliti analisis menggunakan metode Miles dan Huberman menggunakan teknik pengumpulan data, reduksi, penyanyian data, dan penarikan kesimpulan.

\section{Reduksi Data}

a. Deskripsi bentuk-bentuk kegiatan pengembangan motorik kasar

Temuan observasi peneliti pada 8 Januari sampai 19 Januari 2019, terlihat bahwasanya kegiatan pengembangan motorik kasar di Taman Kanak-kanak Kartika 1-63 dilakukan secara bervariasi yaitu:

1) Pada hari Selasa, 8 Januari 2019 kegiatan permainan kereta api dengan gerakan berjalan dan berlari.

2) Pada hari Rabu, 9 Januari 2019 memantulkan bola ke dinding dengan berjalan pada garis lurus dengan gerakan mengayunkan tangan dan berjalan pada garis lurus. 
3) Pada hari Kamis, 10 Januari 2019 lari estafet kegiatan ini memiliki gerakan berlari.

4) Pada hari Sabtu, 12 Januari Senam dengan gerakan jalan di tempat, melompat, dan tepuk tangan.

5) Pada hari Senin, 14 Januari 2019 permainan mencari kata melalui rintangan memiliki gerakan melompat, dan berlari.

6) Pada hari Selasa, 15 Januari 2019 senam gerakan badan memiliki gerakan jalan di tempat, melambaikan tangan, berputar, dan melompat.

7) Pada hari Rabu, 16 Januari 2019 merangkak, berjalan jongkok, merayap di bawah meja, merangkak naik dan turun dari atas meja.

8) Pada hari Kamis, 17 Januari 2019 mampu menjaga keamanan diri (menirukan cara berjalan di jalan raya) dengan gerakan berjalan, berlari, mengayuh sepeda.

$$
\text { Berdasarkan hasil }
$$

wawancara dengan informan yaitu guru dan kepala sekolah didapatkan informasi bahwa kegiatan pengembangan motorik kasar di Taman Kanak-kanak Kartika 1-63 dilakukan secara bervariasi setiap harinya. Kegiatan yang dilakukan untuk mengembangkan motorik kasar yaitu: berjalan, jalan di tempat, berlari, melompat, jongkok, tepuk tangan, merangkak, merayap, melambaikan tangan, berputar, dan mengayuh sepeda.

Berdasarkan dokumentasi sudah terlihat mengenai bentukbentuk kegiatan pengembangan motorik kasar yang dilakukan setiap harinya secara bervariasi.

b. Deskripsi tentang Keunggulan Dari Kegiatan Pengembangan Motorik Kasar

Berdasarkan hasil temuan observasi pada 8 Januari sampai 19 Januari 2019 keunggulan dari kegiatan pengembangan motorik kasar di Taman Kanak-kanak Kartika 1-63 Padang yaitu :

1) Taman Kanak-kanak Kartika 1-63 padang lebih memperhatikan memperhatikan perkembangan motorik kasar terlihat dengan kegiatan motorik kasar yang muncul setiap harinya secara bervariasi.

2) Kegiatan yang dilakukan mengembangkan kegiatan fisik seperti melakukan permainan- 


\section{Kegiatan Pengembangan Motorik Kasar}

permainan yang menggerakkan seluruh anggota tubuh.

3) Kegiatan yang dilakukan sama dengan kegiatan latihan yang dilakukan militer. Seperti melakukan PBB, membawakan yel-yel setiap pagi, melakukan kegiatan merangkak, berjalan jongkok, dan merayap yang dilakukan dalam satu kegiatan secara berurutan.

Berdasarkan hasil

wawancara dengan informan yaitu guru dan Kepala sekolah Taman Kanak-kanak Kartika 1-63 Padang didapatkan informasi bahwa:

a) Kegiatan pengembangan motorik kasar dilakukan secara bervariasi agar anak tidak mudah bosan.

b) Kegiatan pengembangan motorik kasar yang dilakukan mengembangkan kegiatan fisik dengan melakukan permainan yang dapat menggerakkan seluruh anngota tubuh.

c) Kegiatan yang dilakukan sama dengan kegiatan latihan yang dilakukan oleh militer akan tetapi dilakukan dengan tingkat kesulitan yang berbeda.

Sedangkan berdasarkan dokumentasi sudah terlihat mengenai keunggulan-keunggulan yang terdapat di Taman Kanak-kanak Kartika 1-63 dari setiap kegiatannya.

c. Metode yang di gunakan dalam kegiatan pengembangan motorik kasar

Berdasarkan hasil temuan observasi pada 8 Januari sampai 19 Januari 2019 bahwasanya guru terlihat sudah menggunakan metode yang sudah cukup baik. Metode yang digunakan guru Taman Kanak-kanak Kartika 1-63 Padang adalah metode menyanyi, metode demonstrasi, metode praktek langsung, dan metode bermain peran.

Berdasarkan hasil wawancara dengan informan yaitu guru dan Kepala sekolah Taman Kanak-kanak Kartika 1-63 Padang didapatkan informasi bahwa metode yang digunakan guru dalam pengembangan motorik kasar anak adalah metode benyanyi, metode demonstrasi, metode praktek langsung, dan metode bermain peran. Berdasarkan dokumentasi sudah terlihat mengenai metode yang digunakan guru setiap kegiatannya. 


\section{Arnita Fitri ${ }^{1}$, Syahrul Ismet ${ }^{2}$}

\section{Penyajian Data}

Dari data yang sudah di reduksi, maka dapat disajikan data sebagai berikut :

a. Bentuk-bentuk kegiatan pengembangan motorik kasar

Kegiatan pengembangan motorik kasar dilakukan secara bervariasi setiap harinya seperti :

1) Pada hari Selasa, 8 Januari 2019 berjalan dan berlari.

2) Pada hari Rabu, 9 Januari 2019 berjalan, dan memantulkan bola.

3) Pada hari Kamis, 10 Januari 2019 berlari.

4) Pada hari Sabtu, 12 Januari 2019 jalan di tempat, melompat, dan tepuk tangan.

5) Pada hari Senin, 14 Januari 2019 berlari dan melompat

6) Pada hari Selasa, 15 Januari 2019 berjalan di tempat, berputar, melambaikan tangan, melompat.

7) Pada hari Rabu, 16 Januari 2019 merangkak, berjalan jongkak, dan merayap.

8) Pada hari Kamis, 17 Januari 2019 berjalan dan berlari.

b. Keunggulan Dari Kegiatan Pengembangan Motorik Kasar Keunggulan dari kegiatan pengembangan motorik kasar di
Taman Kanak-kanak Kartika 1-63

Padang yaitu :

1) Memperhatikan perkembangan motorik kasar dengan kegiatan motorik kasar yang muncul setiap harinya secara bervariasi.

2) Kegiatan yang dilakukan mengembangkan kegiatan fisik seperti melakukan permainanpermainan yang menggerakkan seluruh anggota tubuh.

3) Kegiatan yang dilakukan sama dengan kegiatan latihan yang dilakukan militer.

c. Metode yang Digunakan Guru Dalam Kegiatan Pengembangan Motorik Kasar

Metode kegiatan pengembangan motorik kasar anak di Taman Kanak-kanak Kartika 1-63 Padang sudah bervariasi dan menarik perhatian anak. Metode yang digunakan dalam mengembangkan motorik kasar anak adalah metode menyanyi, metode praktek langsung, metode demostrasi dan metode bermain peran.

\section{Keabsahan Data}

Uji keabsahan data ini menggunakan triangulasi sumber dan teknik. Triangulasi merupakan pengecekan data dari berbagai 
sumber dengan berbagai cara, dan berbagai waktu.

\section{HASIL PENELITIAN DAN PEMBAHASAN}

Berdasarkan hasil temuan khusus penelitian karena penelitian bersifat deskriptif dengan pendekatan kualitatif. Teknik pengumpulan data yang digunakan yaitu observasi, wawancara dan dokumentasi. Dalam hal ini diharapkan terlihat gambaran tentang bagaimana kegiatan pengembangan motorik kasar anak usia dini di Taman Kanak-kanak Kartika 1-63 Padang.

Hasil penelitian ini dibahas berdasarkan teori, sehingga akan terlihat bagaimana keterkaitan antara teori dengan fakta yang terjadi di lapangan. Adapun pembahasannya sebagai berikut:

\section{A. Bentuk-bentuk \\ Kegiatan}

\section{Pengembangan Motorik kasar}

Bentuk-bentuk kegiatan pengembangan motorik kasar anak di Taman Kanak-kanak Kartika 1-63 Padang dilakukan secara bervariasi setiap harinya seperti kegiatan berjalan, jalan di tempat, berlari, melompat, berjongkok, tepuk tangan, merangkak, berjalan jongkok, merayap, melambaikan tangan dan berputar. Kegiatan yang dilakukan adalah kegiatan yang menantang bagi anak dan kegiatan yang dapat menggerakkan seluruh anggota tubuh atau kegiatan yang memerlukan tenaga yang besar.

Sesuai dengan pendapat yang di kemukakan oleh Suryana (2016:155) mengatakan keterampilan motorik itu penting bagi perkembangan self-concept atau kepribadian anak. Stimulasi yang diberikan untuk mengoptimalkan perkembangan motorik anak adalah keterampilan berolahraga (senam), atau menggunakan alat-alat olahraga. Gerakan-gerakan permainan, seperti meloncat, memanjat, dan berlari. Baris berbaris secara sederhana, gerakan-gerakan ibadah sholat. Karena ini merupakan kemampuan motorik kasar.

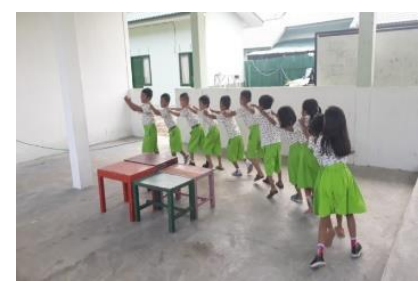

Gambar 1. Permainan kereta api (Arnita, 8 Januari 2019) 


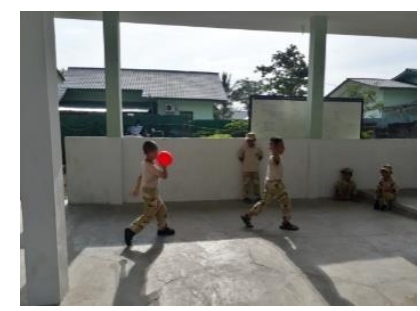

Gambar 2.Memantulkan bola ke dinding dengan berjalan pada garis lurus (Arnita, 9 Januari 2019)

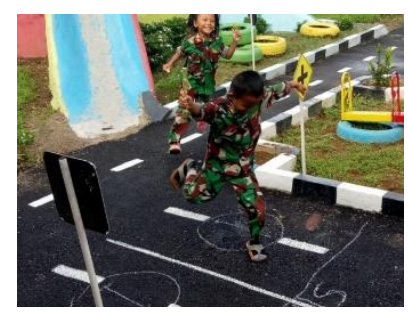

Gambar 3. Lari estafet (Arnita, 10 Januari 2019)

B. Keunggulan Kegiatan Motorik Kasar

Keunggulan kegiatan pengembangan motorik kasar di Taman Kanak-kanak Kartika 1-63

Padang yaitu:

a. Memperhatikan perkembangan motorik kasar dengan kegiatan motorik kasar yang muncul setiap harinya secara bervariasi.

b. Kegiatan yang dilakukan mengembangkan kegiatan fisik seperti melakukan permainanpermainan yang menggerakkan seluruh anggota tubuh.

c. Kegiatan yang dilakukan sama dengan kegiatan latihan yang dilakukan militer.
Sesuai dengan pendapat yang dikemukakan oleh Samsudin (2008:8) menyatakan bahwa perkembangan motorik merupakan perubahan kemampuan motorik dari bayi sampai dewasa yang melibatkan berbagai aspek perilaku dan kemampuan motorik. Aspek perilaku dan perkembangan motorik saling mempengaruhi dengan lainnya.

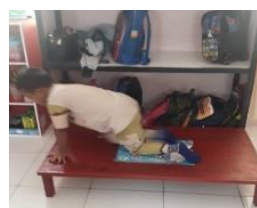

Gambar 4. Merangkak (Arnita, 16 Januari 2019)

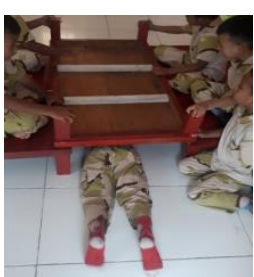

Gambar 5. Merayap (Arnita, 16 Januari 2019)

\section{Metode Yang Digunakan Dalam} Kegiatan Pengembangan Motorik Kasar

Kegiatan pengembangan motorik kasar anak di Taman Kanakkanak Kartika 1-63 menggunakan metode yang bervariasi yaitu metode benyanyi, metode demonstrasi, metode praktek langsung, dan metode bermain peran. 
Sesuai dengan pendapat menurut Fadillah (2014:42-43) bernyanyi merupakan mengeluarkan suara dengan syair-syair yang dilagukan. Mengelola kelas dengan bernyanyi seperti menciptakan dan mengelola pembelajaran dengan menggunakan syair-syair yang digunakan. biasanya syair-syair tersebut disesuaikan dengan materimateri yang akan diajarkan. Menurutnya pendapat bernyanyi membuat suasana menjadi riang dan bergairah sehingga perkembangan anak dapat di stimulasi secara optimal.

Latif (2016:114) hampir dalam setiap kegiatan main akan terjadi pengalaman baru yang menimbulkan kegiatan belajar pada anak. Pengalaman yang dikenal dengan pengalaman belajar tersebut diperoleh oleh anak melalui apa yang mereka lihat, apa yang mereka dengar dan mereka menirukan hal tersebut. Perolehan pengalaman belajar dirancang secara khusus untuk memperlihatkan, dikerjakan dan menjelaskan suatu objek atau proses dari peristiwa yang sedang dilakukan meupakan metode bermain yang disebut demonstrasi.

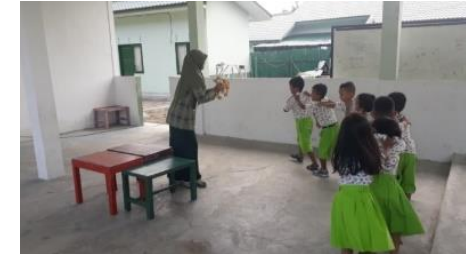

Gambar 6. Metode Bernyanyi (Arnita, 8 Januari 2019)
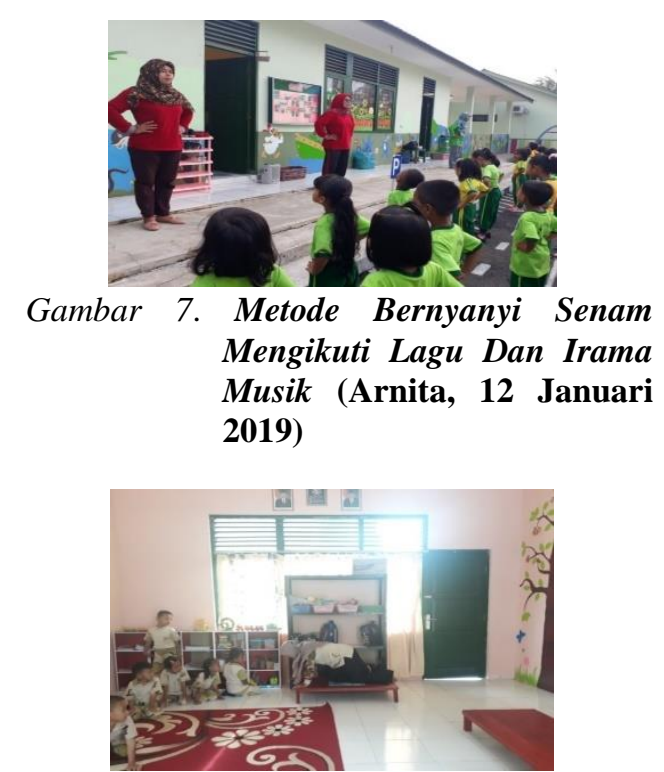

Gambar 8. Metode Demonstrasi (Arnita, 16 Januari 2019)

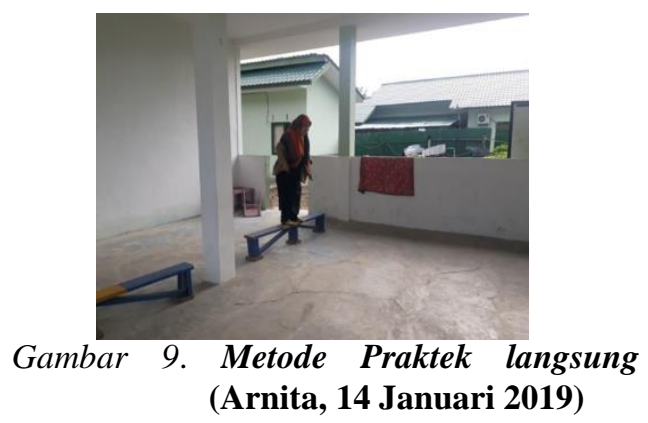


Daftar Rujukan

Fadillah,

$\mathrm{dkk}$.

2014.

EDUTAINMENT

PENDIDIKAN ANAK USIA

DINI Menciptakan

Pembelajaran Menarik,

Kreatif, dan Menyenangkan. Jakarta: KENCANA.

Hasanah, Uswatun. 2016.

Pengembangan Kemampuan

Fisik Motorik Melalui

Permainan Tradisional Bagi

Anak Usia Dini. Vol 5. No

1 .

Iswantiningtyas, Veny, dan Intan Prastihatari Wijaya. 2015.

Meningkatkan Kemampuan

Motorik Kasar Anak Usia

Dini Melalui Permainan

Tradisional Gobak Sodor.

Vol 1. No 3.

Latif, Mukhtar, dkk. 2013. Orientasi

Baru Pendidikan Anak Usia

Dini. Jakarta:

PRENADAMEDIA GRUP.

Magdalena, Lenvita. 012.

Peningkatan Motorik Kasar

Anak Melalui Bermain Bola

Ring Di Taman Kanak-

kanak Nurul Wathan

Kabupaten Pesisir Selatan.

Vol 1. No 1.

Samsudin. 2008. Pembelajaran Motorik Di Taman KanakKanak. Jakarta: Litera.

Suryana, Dadan. 2016. Stimulasi \& Aspek Perkembangan Anak. Jakarta:

KENCANA 
Kegiatan Pengembangan Motorik Kasar 